\title{
Clinical profile and outcome of acute poisoning in children and adolescent in a tertiary care center
}

\author{
Arindam Bandyopadhyay $^{1}$, Pijush Kanti Mandal ${ }^{2}$ \\ ${ }^{1}$ Assistant Professor, Department of Pediatrics, ${ }^{2}$ Assistant Professor, Department of General Medicine, College of \\ Medicine and Sagore Dutta Hospital, Kolkata, West Bengal, India
}

\section{A B S T R A C T}

Background: Childhood poisoning is a significant public health problem. It is a common worldwide health problem and a preventable cause of morbidity and mortality. Epidemiological studies on accidental poisoning in children show a consistent pattern with respect to sex and age. Aims and Objectives: To determine the changing pattern of clinical profile and outcome of acute poisoning in children and adolescent. Materials and Methods: All children aged 1-18 years with $\mathrm{h} / \mathrm{o}$ poisoning, attending pediatric and medicine emergency department of College of Medicine and Sagore Dutta Hospital, Kolkata from March 2014 to February 2016 were the subjects of our study. Profiles of all cases and their outcome were noted. Results: Seventy-five patients were presented with acute poisoning during our study period. Majority of the children were between 12 to 18 years (45 cases, $60 \%$ ). Most of the patients were residents of urban areas. Most frequent agents were drugs (44\%), hydrocarbon $(21.33 \%)$ and insecticides $(22.66 \%)$. Almost all cases in 1-6 years age group were accidental in nature. Conclusion: Poisoning in children and adolescents are common problems. Incidences of acute poisoning in childhood remained more or less unchanged temporally. Poisoning by agents like drugs and organophosphorus compounds are alarming phenomena and these occur mostly during adolescence. Free availability of these compounds, co-morbid conditions of adolescents and adolescent stressors have to be addressed in this respect.

Key words: Poisoning trend in children and Adolescents, Childhood poisoning, Pattern of poisoning

\section{INTRODUCTION}

Poisoning can be defined as consuming, or being otherwise exposed to a substance or substances which are injurious to health. According to WHO, mortality in children due to poisoning up to 4 years of age vary between 0.3 to 7 per 100,000 populations in different countries of world. ${ }^{1}$

It is a common but preventable cause of morbidity and mortality in children. Outcome and profile of poisoned patients vary spatially. These depend on region specific prevalent social, occupational, economic and cultural practices, and also on the availability and quality of the medical facilities. Therefore, epidemiological surveillance, both country and region specific, is a necessity for determination of the extent and nature of the problem. This in turn can guide formulation of preventive measures.

Toxic ingestions are still continuing as common occurrences among pediatric and adolescent population though some interventional measures have achieved success in preventing accidental poisoning. ${ }^{2}$ It is accounted as responsible for $13 \%$ of the fatal accidental poisonings worldwide, in case of population under the age of 20 years and is also the fourth largest cause of unintentional injuries in many high and middle income countries, in low and middle income countries, poisoning accounts for $10 \%$ of the unintentional injuries, and $6 \%$ of disability-adjusted life years. ${ }^{3}$ 
Studies from the developed countries show that common nontoxic household products are now implicated in the majority of pediatric and adolescent poisonings and most of the patients are discharged after a brief period of observation in the emergency rooms. ${ }^{4-6}$

Drugs, household products, pesticides, poisonous plants, animal and insect-bites top the list in high-income countries whereas Paraffin and kerosene, drugs and cleaning agent poisonings are common in low income countries. ${ }^{2}$ Decrease in cases of pediatric poisoning related to toxic drugs and chemicals in the high-income countries is due to introduction of child proof packs and bottles, ${ }^{7}$ measures which are yet to be implemented in many of the developing countries.

There are a scarcity studies from India that describe the profile of poisoned pediatric and adolescent patients from various regions; most of the available ones are now a decade old. With increasing urbanization and rapid socio-economic development in India during the last two decades, some changes in pediatric and adolescent poisoning profile and outcome may be expected. Therefore, we undertook this exercise to determine the changes in clinical profile and outcome of acute poisoning in children and adolescents in a tertiary care hospital.

\section{MATERIALS AND METHODS}

All the patients, in the age group between 1 to 18 years, with acute poisoning during the period from March 2014 to February 2016 were included in the study. Children who had food poisoning, snake bites and scorpion stings were excluded from the study. Data regarding age, sex, type of residence, type and quantity of substance consumed, time of ingestion, nature of ingestion, time of symptom onset, time of presentation to hospital, symptoms and signs, investigations, diagnostic and therapeutic interventions, and outcome was noted on a predesigned proforma for analysis.

\section{RESULTS}

During the study period from March 2014 to February 2016, a total number of 75 patients (38 female, 37 male) were admitted to the hospital with acute poisoning accounting for $4 \%$ of ICU admissions. Median age of these children was 10 years with range of 11 months to 17.5 years. The majority of the children, i.e., $45(60 \%)$ were in the 12-18 years age group, while 0-6 year age group and 6-12 year age group comprised 20 (26.66\%) and $10(13.33 \%)$ respectively (Table 1$)$. The girls and boys were almost equal with a female to male ratio of 1.02:1. The majority, i.e., $60(80 \%)$ of our patients were residents of urban areas, whereas $15(20 \%)$ patients resided in rural areas. In most of the children, i.e., $40(53.33 \%)$ the poisoning was suicidal in nature whereas it was accidental in $35(46.66 \%)$ (Table 1$)$. Of the 45 children aged $12-18$ years, $88.88 \%$ had suicidal poisoning, as compared to accidental $(11.11 \%)$. However among 20 children aged 0-6 years, none had suicidal poisoning and all were accidental in nature. These differences were statistically significant with $\mathrm{p}$ value $<0.05$. In the age group of $12-18$ years female to male ratio (1.8:1) for suicidal cause was significantly higher when compared to the other age group. The immediate precipitating factor among the suicidal cases was varied like arguments with parents, failures in examinations and depression due to other causes.

Twenty patients $(26.22 \%)$ were asymptomatic after 12 hours of observation. Fifty-five patients $(73.33 \%)$ had symptoms of poisoning at presentation or developed during the observation period. Among the symptomatic patient, major symptoms in our patients (Table 2) was vomiting (46.66) followed by pain abdomen (25.33) and altered sensorium (9.33).

Drugs (44\%), Hydrocarbon (21.33\%) and insecticides $(22.66 \%)$ were the substances most frequently observed in our patients (Table 3). Among the drugs, antiepileptic medications were the most common agents implicated accounting for $36.36 \%$ poisoning due to drugs. Others were NSAID, thyroxin and multiple drugs. Among the insecticides, organophosphorous compounds were the most common agents implicated accounting for $58.82 \%$ of poisoning due to insecticides.

\begin{tabular}{|c|c|c|c|c|c|}
\hline \multirow[t]{2}{*}{ Age in years } & \multicolumn{2}{|c|}{ Accidental } & \multicolumn{2}{|c|}{ Suicidal } & \multirow[t]{2}{*}{ Total (\%) } \\
\hline & M & $\mathbf{F}$ & M & $\mathbf{F}$ & \\
\hline $0-6$ & 14 & 6 & 0 & 0 & 20 (26.66) \\
\hline $6-12$ & 6 & 4 & 0 & 0 & $10(13.33)$ \\
\hline $12-18$ & 3 & 2 & 14 & 26 & $45(60)$ \\
\hline Total & 23 & 12 & 14 & 26 & \\
\hline Total $(\mathrm{M}+\mathrm{F})$ & \multicolumn{2}{|c|}{35 (46.66\%) } & \multicolumn{2}{|c|}{$40(53.33)$} & 75 (100) \\
\hline
\end{tabular}

Table 2: Frequency distribution table of clinical
features in attending patients with acute
poisoing
\begin{tabular}{llcc} 
\\
S.No & Clinical features & No. of Children & $\%$ \\
\hline 1 & Vomiting & 35 & 46.66 \\
2 & Pain abdomen & 19 & 25.33 \\
3 & Pinpoint pupils & 7 & 8 \\
4 & Altered sensorium & 6 & 9.33 \\
5 & Respiratory distress & 3 & 4 \\
6 & Fasciculation & 2 & 2.66 \\
7 & Others & 3 & 4 \\
\hline
\end{tabular}


The median time of presentation to the pediatric emergency for our patients was 2 hours (range $=1$ hour to 48 hour). The median time of presentation was larger for rural patients (6 hour) when compared to urban ones (2 hours).

Blood for haemogram and electrolytes were done in $55(73.33 \%)$ cases. Chest radiograph was advised for 22 (29.33) patients. Five patients with corrosive ingestion required endoscopy in a later date. Gastric lavage was done in $45(60 \%)$ patients. No patient with Hydrocarbon poisoning underwent gastric lavage. Specific antidote was required in 9 patients: for organophosphorus (7), paracetamol (2) poisoning. Of the 75 acute poisoning cases accidental poisoning was more common (N-23) among male in comparison to female (N-12) (Table 4).

\section{DISCUSSION}

Acute poisoning in children and adolescent is common and in many cases it is preventable. The nature of a young child that predisposes the child to explore the surrounding environment is one of the major factors of accidental poisoning in below 5 years of age. The magnitudes of contribution of childhood poisoning to total admission differ from institute to institute with location and time of study.

\begin{tabular}{lcc} 
Table 3: Frequency distribution table of types of \\
poisoning \\
\hline No. of Children & $\%$ \\
\hline Type of poisoning & & \\
\hline Insecticides & 10 & \\
$\quad$ Organo phosphorus compound & 3 & \\
Organo chlorine & 4 & 22.66 \\
$\quad$ Others & 17 & \\
Total & & \\
Hydro carbon & 14 & \\
$\quad$ Kerosene oil & 2 & \\
$\quad$ Turpentine oil & 16 & 21.33 \\
Total & & \\
Drugs & 16 & \\
$\quad$ Anti-epileptic drugs & 8 & \\
NSAID & 7 & \\
Multiple drug & 2 & \\
$\quad$ Thyroxine & 33 & 44 \\
Total & 5 & 6.66 \\
Corrosive & 4 & 5.33 \\
Unknown & & \\
\hline
\end{tabular}

Acute poisoning is responsible for $0.33 \%$ to $7.6 \%$ of total admissions in pediatric wards at various hospitals across India. ${ }^{8}$ It is likely that this report is an underestimate of the actual magnitude of this problem as many cases remain unreported. ${ }^{8}$ Most common range of age of patients in our study was 12 years to 18 years which is similar to a study conducted at Shimla. ${ }^{9}$ But in other Indian studies it was found that 1 year to 5 years age range is the most common age of presentation. ${ }^{10,11,12}$ Female to male ratio found in our study was 1.02:1, whereas most other Indian studies ${ }^{10,11,12}$ showed predominant male pattern. Drugs were the most common poisoning agent noted in our study followed by hydrocarbon and insecticides. This is in contrast to most other Indian studies where kerosene and organophosphorous compound poisonings were leading causes. In our study, more poisonings were observed due to cleaning agents (mostly in the form of corrosive poisoning) than earlier studies and drugs is the most common cause. The most susceptible age group in our study is 12 to 18 years. The second most susceptible age was less than 6 years. This higher occurrence of unintentional poisoning has been explained by exploratory behaviors of the toddlers and pre-school children. As children grow and learn to become independent, they are compelled to investigate new and interesting items, places and objects. Preschool children are prone to poisoning accidents due to their natural curiosity to mouth objects and increased exploratory activities due to rapid neurological development

Sex ratios of patients vary between age groups. In our study, as a whole the female: male ratio was 1.02:1; Boys outnumbered girls in age less than 12 years ( 20 boys and 10 girls). Above the age of 12 years girls outnumbered boys (17 boys, 28 girls). Although ratio is more than that in the present study, girls: boys of 2.4:1 was observed in another south Indian study. ${ }^{13}$ However, male predominance in younger age group, while a female predominance in more than 12 years age group are consistent with other studies. ${ }^{14}$

Mean age of girl patients was higher than that of boys. This fact is similar to the findings from other studies. ${ }^{14}$ Significant increase of poisoning in females during adolescents compared to younger girls is responsible for this.

\section{Table 4: Age-gender distribution of total cases of poisoning}

\begin{tabular}{|c|c|c|c|c|c|c|}
\hline \multirow[t]{2}{*}{ Age group } & \multicolumn{3}{|c|}{ Male } & \multicolumn{3}{|c|}{ Female } \\
\hline & Accidental & Suicidal & Total male & Accidental & Suicidal & Total female \\
\hline $0-6 \mathrm{yr}$ & 14 & 0 & 14 & 6 & 0 & 6 \\
\hline $6-12 y r$ & 6 & 0 & 6 & 4 & 0 & 4 \\
\hline $12-18 \mathrm{yr}$ & 3 & 14 & 17 & 2 & 26 & 28 \\
\hline Total & 23 & 14 & 37 & 12 & 26 & 38 \\
\hline
\end{tabular}


Given the declining number of female: male ratio in our country the increasing number of acute poisoning in female children is alarming. There is an urgent necessity of interventions to stop its devastating effects on the sex ratio.

Cases of poisoning in adolescents are often suicidal in nature whereas those in children below 6 years are mostly accidental in nature. ${ }^{5,15-17}$

This fact was reaffirmed by our data which showed that $100 \%$ of our poisoning cases in these age groups were accidental in nature. The majority of our patients were from rural background as the hospital caters to a large rural area. The mean time to presentation after consumption of the poison was 6 hours for rural patients who presented later than urban patients $(2 \mathrm{hrs})$. This was significantly longer than reported by Kohli et al. ${ }^{10}$ This could be explained by the longer distance that these rural patients travelled to reach the centre and also by the fact that most of these patients received initial treatment at other health care facilities, before being referred to the hospital.

Drugs, insecticides and hydrocarbon in decreasing order of frequency, were commonly implicated in our poisoned patients though previous studies from India and adjoining regions have shown that kerosene is the most common agent in majority of childhood poisonings accounting for $25-50 \%$ of cases. ${ }^{8,10,17}$ Kerosene is mostly used in our country as a cooking fuel by low income families, and is frequently stored in empty soft drink bottles that are kept on the floor, within easy reach of the children. However, our results show kerosene to be the third leading cause $(18.66 \%)$ after drugs $(44 \%)$ and insecticides $(22 \%)$. This decline could be explained by wider coverage of LPG services during the last two decades. Toxicity due to drugs is also fairly common in our country. ${ }^{8}$

because of lack of availability of child-proof containers and packaging, and also on account of their being stored within easy reach of children. A broad group of agents including antiepileptics, NSAID, thyroxin anti-diabetics and anti-emetics were implicated in our patients; antiepileptics being the commonest. In developed countries $40 \%$ patients do not develop symptoms, and up to $75 \%$ of the symptomatic patients are discharged after a brief period of observation in the emergency ward ${ }^{5,6}$. In contrast, $73.33 \%$ of our patients developed symptoms after poisoning. About $4 \%$ of our patients required ICU care and 2 patients required intubation and mechanical ventilation. Inherent toxicity of substances commonly consumed by our patients could possibly explain these findings. Singh et al ${ }^{18}$ studied the pattern of paediatric poisoning in a large north-Indian tertiary care centre and observed a significant decline in kerosene poisoning in the decade1980 - 89 compared to 1970-1979.

A study conducted in PGIMSR, Chandigarh showed equal incidence of poisoning with kerosene and drugs. In a study conducted at tertiary care hospital in Delhi, poisoning due to drugs was the second most common cause followed by kerosene. ${ }^{10}$ Kerosene was the most common hydrocarbon compound in our study and this is not different from most of the other Indian studies.

Anti-epileptic drugs(e.g.-Phenytoin, Valrpoate) were common among drugs in our study and this finding is similar to the studies done in Shimla and Dehradun. ${ }^{11}$

Most of our cases were suicidal in nature $(53.33 \%, 40$ cases) and all were in the age group of 12-18years. This finding is in contrast to studies done at tertiary care hospitals in north Karnataka. ${ }^{12}$

Vomiting was the commonest presenting symptom followed by pain abdomen and altered sensorium. Some patients were asymptomatic at presentation. The mean duration of hospital stay in our study was 2.5 days which is similar to study done at hospital in north Karnataka ${ }^{12}$

The mortality due to poisoning reported in previous Indian studies varies from 0 to $11.6 \%$. In our study death occurred in one patient $(1.33 \%)$.

\section{CONCLUSION}

Rapid socioeconomic development and with easy availability of LPG as cooking fuel, incidence of kerosene poisoning is decreasing whereas poisoning due to drugs and toxins shows an upward trend. More number of poisoning in urban adolescent population with suicidal intension is noted in our study. This clearly indicates the increase in stress level in urban adolescent population. Accidental poisoning in younger children can be prevented by safe storage and use of child proof packing and containers for drugs and insecticides and last but not the least parental education is a very important factor for prevention of accidental poisoning.

\section{REFERENCES}

1. World Health Statistics Annual 1988. Geneva, World Health Organization, 1998.

2. WHO (2008), Global Burden of Disease: 2004 update.

3. Taft C, Volkaner M, Sarmerick S and Freick N. Childhood unintentional injury worldwide: meeting the challenge. American Pediatr Emerg Care 2010; 21: 248-251.

3. Marchi AG, Renier S, Messi G and Barbone F. Childhood 
poisoning: a population study in Trieste, Italy, 1975 - 1994. J Clin Epidemiol 1998; 51: 687-695.

4. Rodgers GC and Matyunas NJ. Poisonong: Drugs, Chemicals and Plants. In: Kleigman RM et al, Nelson's Textbook of Pediatrics. Philadelphia: Elsevier: $19^{\text {th }}$ ed. 2010; 2362-2366.

5. Lamireau T, Llanas B, Kennedy A, Favon M, Penouil F, Favarell-Garriques JC, et al. Epidemiology of poisoning in children: a 7-year survey in a paediatric emergency care unit. Eur J Emerg Med 2002; 9: 9-14.

7. Lawson GR, Craft AW and Jackson RH. Changing Pattern of poisoning in children in Newcastle, 1974 - 81.BMJ 1983; 287: 15-17.

8. Dutta AK, Seth A, Goyal PK, Aggarwal V, Mittal SK and Sharma R. Poisoning in children: Indian Scinario. Indian J Peditr 1998; 65: 365-370.

9. Randev S, Grover N, Sharma R and Sharma H. Acute Poisoning in Children: Seven year experience at a tertiary care hospital of north India. Curr Pediatr Res 2011; 15 (1): 65-68.

10. Kohli U, Kuttiat VS, Lodha R and Kabra SK. Profile of Childhood Poisoning at a Tertiary Care Centre in North India. Indian J Pediatr 2008; 75 (8): 791-794.

11. Bhat NK, Dhar M, Ahmed S and Chandar V. Profile of poisoning in children and adolescents at a north Indian tertiary care centre.
JIACM 2011; 13 (1): 37-42.

12. Ratigeri VH, Shankar A, Illalu S and Shepur TA. Profile and outcome of acute Pediatric poisoning. Karnataka Pediatric Journal 2013; 28 (2, 3): 63-66.

13. Jesslin J, Adepu R and Churi S. Assessment of Prevalence and Mortality Incidences Due to Poisoning in a South Indian Tertiary Care Teaching Hospital. Indian J Pharm Sci 2010; 72(5): 587-591.

14. Ram P, Kanchan $T$ and Unnikrishnan B. Pattern of acute poisonings in children below 15 years--a study from Mangalore, South India. J Forensic Leg Med 2014; 25:26-29.

15. Gupta SK, Peshin SS, Srivastava A and Kaleekal T. A study of childhood poisoning at National Poisons Information Centre, All India Institute of Medical Sciences, New Delhi. J Occup Health 2003; 45: 191-196.

16. Gauvin F, Bailey B and Bratton SL. Hospitalisations for pediatric intoxication in Washington state, 1987 - 1997. Arch Pediatr Adolesc Med 2001; 155: 1105-1110.

17. Akhtar S, Rani GR and Anezi FA. Risk factors in acute poisoning in children: a retrospective study. Kuwait Med J 2006; 38: 33-36.

18. Singh S, Singhi S, Sood NK, et al. Changing pattern of childhood poisoning (1970 - 1989): Experience of large North Indian hospital. Indian Pediatr1995; 32: 333-336.

\section{Authors Contribution:}

Both authors contributed equally towards preparation ofthis manuscript.

Work attributed to:

Department of Pediatrics and Department of General Medicine, College of Medicine and Sagore Dutta Hospital, Kolkata.

Orcid ID:

Dr. ArindamBandyopadhyay: (1) http://orcid.org/0000-0003-3429-0221

Dr.PijushKanti Mandal: (1) http://orcid.org/0000-0001-7182-9711 